\title{
Gynaecologic Laparoscopic Surgery Using Spinal Anaesthesia - A Retrospective Observational Study
}

\author{
Jayanth Nagendranath Chilkund ${ }^{1}$, Jeevan Jayant Gadgil ${ }^{2}$ \\ ${ }^{1}$ Department of Obstetrics and Gynaecology, Pt. MMM Shatabdi Hospital, Mumbai, Maharashtra, \\ India. ${ }^{2}$ Department of Anaesthesia, Pt. MMM Shatabdi Hospital, Mumbai, Maharashtra, India.
}

\section{ABSTRACT}

\section{BACKGROUND}

Laparoscopy is traditionally done under General Anaesthesia (GA) with endotracheal intubation. As the number of cases of laparoscopy increased over the years, regional anaesthesia has been quite frequently used for laparoscopy.

\section{METHODS}

A total of 495 cases of laparoscopic surgeries done in the age group 12 to 47 years during the period August 2015 till September 2019 was considered. Spinal anaesthesia was administered with 25G spinal Needle at L4-L5 intervertebral space with $3-4 \mathrm{ml}$ bupivacaine $(0.5 \%$, heavy) and the surgeries were completed. The segmental level achieved was T-6. Intra-abdominal pressure after $\mathrm{CO}_{2}$ insufflation for pneumoperitoneum was maintained at 10-12 mmHg. Post-operative monitoring was done.

\section{RESULTS}

Only 15 cases (3\%) required midazolam. 2 patients stayed for $>48$ hrs post-surgery (0.4\%). 4 GA cases required immediate analgesic infusion. In SA cases, analgesic was required almost 2-3 hours after the surgery was over. Onset of bowel sounds was early with SA cases. In the 4 GA cases $(0.8 \%)$ PONV was noted. Two patients $(0.4 \%)$ had spinal headache. 6 patients experienced post laparoscopic shoulder pain (1.21\%).

\section{CONCLUSIONS}

Spinal Anaesthesia provides a good field for gynaecologic laparoscopic surgery with excellent muscle relaxation, decreased surgical bed oozing, and a rapid return of gut function, good post-operative analgesia, and decreased incidence of PONV than GA.
Corresponding Author: Dr. Jayanth Nagendranath Chilkund, \#102, Udhyan CHS, Plot No. 63, Sector 21, Nerul, Navi Mumbai, Maharashtra, India.

E-mail: jayanthchilkund@gmail.com

DOI: $10.14260 /$ jemds/2020/199

Financial or Other Competing Interests: None.

How to Cite This Article:

Chilkund JN, Gadgil JJ. Gynaecologic laparoscopic surgery using spinal anaesthesia- a retrospective observational study. J. Evolution Med. Dent. Sci. 2020;9(12):924-927, DOI: 10.14260/jemds/2020/199

Submission 15-01-2020,

Peer Review 26-02-2020,

Acceptance 04-03-2020,

Published 23-03-2020.

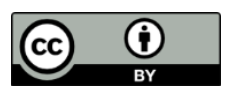

\section{KEY WORDS}

Laparoscopy, Gynaecology, Spinal Anaesthesia 


\section{BACKGROUND}

Laparoscopy is traditionally done under general anaesthesia (GA) with endotracheal intubation. To provide a good operative field in laparoscopy, multiple ports need to be placed for adequately exposing the organs. This is augmented by correct positioning, decompression of the gastrointestinal tract (GI tract), adequate pneumoperitoneum and good muscle relaxation, for which traditionally general anaesthesia is preferred. Routinely most of the surgeries in Gynaecology are done under Spinal or Epidural anaesthesia. General Anaesthesia is used only when there is a specific indication for it or if the patient has asked for it specifically. Most of the surgeries done routinely in gynaecology are being changed from laparotomy to laparoscopy. In GA, an extra time for induction and reversal needs to be kept in mind while calculating the total time of the surgery. Also, Spinal anaesthesia (SA) is more economical than GA. Traditionally general anaesthesia is used with the apprehension that adequate relaxation may not be possible in spinal anaesthesia for laparoscopy. As the number of cases of laparoscopy increased over the years, regional anaesthesia has been quite frequently used for laparoscopy. There are various studies which have described the use of spinal anaesthesia for laparoscopic surgeries of Gall Bladder and Appendix.(1,2) There are also studies which have stated that use of epidural or spinal anaesthesia is quite safe for laparoscopy in ASA grade I patients.(3)With Spinal Anaesthesia, excellent muscle relaxation, decreased surgical bed oozing, and a rapid return of gut function, good post-operative analgesia, decreased incidence of PONV(post-operative nausea and vomiting) are seen compared to General Anaesthesia. Also, spinal anaesthesia is cost effective and timesaving. There are studies to show efficacy of spinal anaesthesia for short duration gynaecologic laparoscopy.(4) The purpose of this retrospective study is to show that Spinal Anaesthesia is quite suitable for gynaecological laparoscopic surgery.

\section{METHODS}

The present study is a retrospective observational study of patients having gynaecologic laparoscopic surgery while under Spinal Anaesthesia (SA). The study was conducted after ethical clearance. The duration of the study was from August 2015 till September 2019 at a peripheral care centre. A total of 495 cases of laparoscopic surgeries were done in the age group 12 to 47 years during this period. Of these 491 were given SA. Only 4 cases were given GA as these four patients were opting for GA. Pre-operative evaluation was done with proper history, examination about MPC (Mallampati classification)(5) and ASA (American Society of Anesthesiologists) ${ }^{(6)}$ assessment, regarding ease of giving GA if required. All the patients were counselled regarding Spinal Anaesthesia and 491 patients accepted the same willingly and informed consent taken according to the standard protocol. Standard operating procedures as per http://www.patientsconsent.com/ followed. The list of the surgeries performed is given in Table 1 and 2 .
On the day of surgery, premedication with intramuscular Glycopyrrolate 30 mins before surgery was done. Preloading with Ringer lactate was done. In the Operation Theatre, Spinal anaesthesia was given with 25G spinal Needle at L4-L5 intervertebral space with 3-4 ml Bupivacaine (0.5\%, heavy). Head down tilt of 10-20 degrees for fixation of the drug. Once the level was established, lithotomy position was given to the patient. The segmental level achieved was T-6. During surgery, Oxygen was administered at 3-4 litres per min. Apprehensive patient was mildly sedated with IV Midazolam. Patients were monitored for pulse rate, blood pressure, saturation, ECG, $\mathrm{ETCO}_{2}$ (through oxygen mask). Intra operatively, the intra peritoneal pressure was kept between 10-12 mmHg. At the end of the surgery, the $\mathrm{CO}_{2}$ gas in the abdomen was completely removed and the incision sutured. Post operatively, patients were examined at 2 hrs., 6 hrs., 12 hrs. and $24 \mathrm{hrs}$. and SOS if required, for pain (verbal numeric pain scale), incidence of nausea and vomiting, mobility, awakeness and readiness for discharge. Patients were routinely followed up at one-month post-surgery.

\section{RESULTS}

\begin{tabular}{|c|c|}
\hline Types of Surgery & Number \\
\hline Diagnostic Laparoscopy with CPT & 34 \\
\hline Ovarian cystectomy & 24 \\
\hline BSO ( post hysterectomy) & 3 \\
\hline Ectopic pregnancy & 4 \\
\hline PCOD drilling & 3 \\
\hline Hysteroscopic septum resection & 1 \\
\hline Hysteroscopic polypectomy & 1 \\
\hline Lap Myomectomy & 3 \\
\hline TLH & 17 \\
\hline Laparoscopic Omental biopsy for TB & 1 \\
\hline Hysteroscopic removal of CuT & 3 \\
\hline Lap sacro suspension & 1 \\
\hline Interval Lap Tubal Ligation & 199 \\
\hline MTP with Lap Tubal Ligation & 201 \\
\hline Total & $\mathbf{4 9 5}$ \\
\hline Table 1. Type and Number of Surgeries \\
\hline
\end{tabular}

\begin{tabular}{|c|c|}
\hline Anaesthesia & Number \\
\hline Spinal Anaesthesia & 491 \\
\hline General Anaesthesia & 4 \\
\hline \multicolumn{2}{|c|}{ Table 2. Type of Anaesthesia Used } \\
\hline
\end{tabular}

\begin{tabular}{|c|c|}
\hline Features & Findings \\
\hline Awakeness & Always awake \\
\hline Analgesic doses & $\begin{array}{l}\text { Started by 3-4 hours after induction, } \mathrm{A} \\
\text { maximum two doses in } 24 \mathrm{hrs} \text {. } \\
\text { Paracetamol } 1000 \mathrm{mg} \text { infusion. }\end{array}$ \\
\hline PONV & $4 / 495$ cases $0.8 \%$ \\
\hline Ambulation & At $4 \mathrm{hrs}$ post-surgery \\
\hline Oral intake & At $6 \mathrm{hrs}$ post-surgery \\
\hline Stay in Hospital $24 \mathrm{hrs}$ post-surgery & 478 cases $96 \%$ \\
\hline Stay in hospital $48 \mathrm{hrs}$ post-surgery & 15 cases $3 \%$ \\
\hline Stay in hospital $>48 \mathrm{hrs}$ post-surgery & 2 cases $0.4 \%$ \\
\hline Spinal headache & 2 cases $0.4 \%$ \\
\hline Post laparoscopic shoulder pain & 6 cases $1.21 \%$ \\
\hline \multicolumn{2}{|c|}{ Table 3. Post-Operative Recovery } \\
\hline
\end{tabular}

All the 495 cases were uneventful. Only 15 cases (3\%) required Midazolam intra-operatively as they were very apprehensive and complained of fullness and discomfort during $\mathrm{CO}_{2}$ insufflation. And these patients stayed in the hospital for 48 hrs. Post-surgery. 2 patients stayed for $>48$ hrs. post-surgery $(0.4 \%)$. Only one infusion of $1000 \mathrm{mg}$ Paracetamol was required as analgesic for all the SA cases and later oral analgesics. Only the four GA cases required immediate analgesic infusion while in SA cases the analgesic 
was required to be administered 3-4 hours after induction, almost 2-3 hours after the surgery was over. Onset of bowel sounds was early with SA cases and pts. were started on orals by 6 hours after surgery. Only in the 4 GA cases $(0.8 \%)$ PONV was noted. Two patients $(0.4 \%)$ had Spinal headache for which stay was prolonged. Only 6 patients experienced post laparoscopic shoulder pain $(1.21 \%)$

\section{DISCUSSION}

All abdominal and vaginal surgeries in Gynaecology department are routinely carried out under Spinal or Epidural anaesthesia. General anaesthesia is used when there is contraindication for spinal anaesthesia or when the patient prefers it. For laparoscopic surgeries traditionally general anaesthesia is used with endotracheal intubation. Since the time required for open or laparoscopic surgery was almost equal it was decided to do the laparoscopic cases under Spinal anaesthesia. After first few being so successful, spinal anaesthesia for all the gynaecologic laparoscopic cases was opted for. As the patients were awake during surgery any complications could easily be picked up early as the patient herself would tell us the symptoms. All the potential ventilation induced problems including an increase in mechanical ventilation to achieve adequate ventilation pressure exists during General Anaesthesia. While in Spinal Anaesthesia this does not exist. Intra-abdominal pressure was maintained at $10-12 \mathrm{mmHg}$. The $\mathrm{CO}_{2}$ insufflation while causing pneumoperitoneum can affect the cardiovascular system. This is mainly dependent on the intra-abdominal pressure. At lower intra-abdominal pressures of less than 15 $\mathrm{mmHg}$, the venous return is augmented due to the emptying of splanchnic vessels, and thus cardiac output and blood pressure are not decreased. At higher intra-abdominal pressures of more than $15 \mathrm{mmHg}$, due to compression of inferior vena cava and other collaterals, the venous return is decreased, thus reducing cardiac output and blood pressure.(7)

SA induces some amount of hypotension. Pneumoperitoneum that is induced also causes a rise in intraabdominal pressure and this could be another cause for persistence of hypotension, This is comparable to hypotension occurring in patients undergoing open surgery with SA,(1) While Bernd(8) reported hypotension in 5.4\% of their SA patients, Palachewa ${ }^{(9)}$ had an incidence of $15.7 \%$, Throngnumchai( $\left.{ }^{10}\right) 20.2 \%$, and Hyderally(11) reported a $10 \%$ to $40 \%$ incidence. This then conclusively proves that the incidence of hypotension is no different whether laparoscopic surgery or open surgery is being done with SA and that a moderate intra-abdominal pressure maintained $10-12 \mathrm{mmHg}$ does not add to the problem of decreased venous return and persistence of hypotension. There is an added advantage of decrease in surgical bed oozing because of hypotension, bradycardia and improved venous drainage associated with SA. Thus, there is less oozing in SA than in GA during Surgery. Pulmonary function takes 24 hours to return to normal after laparoscopic surgery performed under GA.(12)Increased $\mathrm{PaCO}_{2}$ concentrations after $\mathrm{CO}_{2}$ pneumoperitoneum has been observed in patients under GA as compared to when the patients are breathing spontaneously.(13) This is a distinct advantage of SA over GA. Spinal or Epidural Anaesthesia does not cause ventilatory depression.(14) The average time required for major laparoscopic surgery like total laparoscopic hysterectomy was 2 hours which was identical with the time taken for open hysterectomy. When patients are under GA, an additional time for intubation and extubation with reversal gets added up to an extra 1 hour. Hence in SA, the time required from wheeling in to wheeling out was reduced, thus allowing the surgical team to take up more number of cases in the same OT time. The peripheral centre where these surgeries were carried out is a high output centre with more than 1200 cases being operated every year. Hence this saving of time enabled the surgical team to take up more cases.

In Pneumoperitoneum under epidural or spinal anaesthesia, breathing spontaneously results in an increase in minute ventilation with unchanged $\mathrm{ETCO}_{2}$. It provides excellent post-operative analgesia with lesser incidence of Post-Operative Nausea and Vomiting (PONV).(15),(16)PONV has highest incidence in GA when Nitrous, Opiate and reversal drugs are used.(9) Patients with GA have an additional problem of stomach inflation during mask ventilation, which needs to be deflated with Ryle's tube. This problem does not occur in SA. Post laparoscopic shoulder pain is seen when the intra-abdominal pressure is kept high and there remains sufficient residual gas to cause irritation of the diaphragm. The incidence of Post laparoscopic Shoulder pain was seen in 6 patients. The intra-abdominal pressure was kept between 10-12 $\mathrm{mmHg}$, and the abdomen was deflated well at the end of the surgery.(10) Complications specific to GA, including cardiac, myogenic, and possible cerebral complications, do not occur with SA. Also, the complications following endotracheal intubation like sore throat, laryngeal oedema, hoarseness, and tracheal injuries are avoided. Requirement of analgesia was immediate after GA, while in SA it was after 2-3 hours after surgery. The benefit of prolonged analgesia after SA has also been noted in other studies.(17) All patients were ambulatory by 6 hours and put on orals with onset of bowel sounds. Patients were awake in the entire operative and immediate post-operative time and had a sense of wellbeing. SA is more cost effective than GA.

\section{CONCLUSIONS}

Spinal anaesthesia provides a good field for gynaecologic laparoscopic surgery with excellent muscle relaxation, decreased surgical bed oozing, and a rapid return of gut function, good post-operative analgesia, and decreased incidence of PONV than GA.

\section{REFERENCES}

[1] Sinha R, Gurwara AK, Gupta SC. Laparoscopic surgery using spinal anaesthesia. J Soc Laparoendosc Surg 2008;12(2):133-8.

[2] Singh RK, Saini AM, Goel N, et al. Major laparoscopic surgery under regional anaesthesia: a prospective feasibility study. Med J Armed Forces India 2015;71(2):126-31. 
[3] Erdem VM, Donmez T, Uzman S, et al. Spinal/epidural block as an alternative to general anaesthesia for laparoscopic appendectomy: a prospective randomized clinical study. Wideochirurgia I Inne Tech Maloinwazyjne 2018;13(2):148-56.

[4] Stewart AVG, Vaghadi H, Collins L, et al. Small-dose selective spinal anaesthesia for short-duration outpatient gynaecological laparoscopy: Recovery characteristics compared with propofol anaesthesia. Br J Anaesth 2001;86(4):570-2.

[5] Mallampati SR, Gatt SP, Gugino LD, et al. A clinical sign to predict difficult tracheal intubation: a prospective study. Can Anaesth Soc J 1985;32(4):429-34.

[6] Doyle DJ, Garmon EH. American Society of Anesthesiologists Classification (ASA Class). In: Stat Pearls [Internet]. Treasure Island (FL): StatPearls Publishing 2020 Jan - 2020 Feb 17.

[7] Bajwa SJS, Kulshrestha A. Anaesthesia for laparoscopic surgery: general vs regional anaesthesia. J Minim Access Surg 2016;12(1):4-9.

[8] Hartmann B, Junger A, Klasen J, et al. The incidence and risk factors for hypotension after spinal anaesthesia induction: an analysis with automated data collection. Anesth Analg 2002;94(6):1521-9.

[9] Malins AF, Field JM, Nesling PM, et al. Nausea and vomiting after gynaecological laparoscopy: comparison of premedication with oral ondansetron, metoclopramide and placebo. $\mathrm{Br} \mathrm{J}$ Anaesth 1994;72(2):231-3.
[10] Sao CH, Chan-Tiopianco M, Chung KC, et al. Pain after laparoscopic surgery: focus on shoulder-tip pain after gynecological laparoscopic surgery. J Chin Med Assoc 2019;82(11):819-26.

[11] Hyderally $\mathrm{H}$. Complications of spinal anaesthesia. Mt Sinai J Med 2002;69(1-2):55-6.

[12] Palachewa K, Chau-In W, Naewthong $P$, et al. Complications of spinal anaesthesia at Stinagarind hospital. Thai J Anesth 2001;27:7-12.

[13] Throngnumchai R, Sanghirun D, Traluzxamee K, et al. Complication of spinal anaesthesia at Lerdsin hospital. Thai J Anesth 1999;25:24-7.

[14] Ciofolo MJ, Clergue F, Seebacher J, et al. Ventilatory effects of laparoscopy under epidural anaesthesia. Anesth Analg 1990;70(4):357-61.

[15] Sood J. Advancing frontiers in anaesthesiology with laparoscopy. World J Gastroenterol 2014;20(39):1430814.

[16] Wang XX, Zhou Q, Pan DB, et al. Comparison of postoperative events between spinal anaesthesia and general anaesthesia in laparoscopic cholecystectomy: a systemic review and meta-analysis of randomized controlled trials. Biomed Res Int 2016;2016:9480539.

[17] Putensen-Himmer G, Putensen CH, Lammer H, et al. Comparison of postoperative lung function in patient undergoing laparotomy or laparoscopy for cholecystectomy. Am Rev Resp Dis 1992;145:A156 